po, estava querendo construir indústrias pesadas e estava assim utilizando esta oportunidade como um método para reforçar a sua própria. Surgiam vários tipos de problemas nesses acordos por se estar tratando agora com governos estrangeiros, o que levantava questões de como contabilizar os livros no caso de haver dúvidas quanto aos custos. Por isso, nesses acordos, para a coisa poder funcionar como devia, havia sempre substanciais pagamentos prévios: pagamentos para a assistência técnica, etc. E existiam ainda todas as espécies de fórmulas complicadas quanto ao royalty especial por rifle no correr do tempo e tínhamos também sistemas mediantes os quais fornecíamos peças a esses países durante um certo período, o que nos posicionava bem dentro do acordo, com a compensação na mão por parte do autorizante até que o país se achasse realmente em condições de construir um rifle completamente por seus próprios meios. Acho que é preciso ter muito cuidado com isso nos acordos de concessão. Quando se vai ter o retorno econômico no decorrer de um longo período de tempo, o autorizante quererá, realisticamente, assegurar-se desse adequado retorno, ou por antecipação ou por outra forma contratual, antes de colocar de fato outrem no negócio e que o possa gerir daí em diante.

O terceiro acordo a que quero me referir rapidamente é aquele que na realidade considero a fase seguinte em sofisticação no plano de negócio da Fairchild, em 1972. Consideramos que, se realmente queríamos crescer na indústria aeroespacial, não o poderíamos fazer sós. Tínhamos de firmar alianças para entrar na aventura conjunta e fazer as coisas com outros interessados. Em 1980, na seqüência de dezoito meses de trabalho e deliberações e significativos investimentos de base por ambos os lados, entramos numa mais volumosa aventura conjunta com a Scania AB-SAAB, da Suécia, para planificar, desenvolver, fabricar e negociar por todo o mundo um novo avião comercial. De ambos os lados se considerou que o projeto era tão grandioso, os riscos tão grandes e o mercado tão aleatório, perante os dados computarizados, que se tornava mais sensato partiIhar o risco de seguir em frente e, de novo, se puseram várias razões de ambas as partes. $O$ pessoal da $\mathrm{SAAB}$ dispunha de capacidade em engenharia resultante dos seus programas militares; a Fairchild possuía basicamente o seu pessoal técnico ligado aos projetos, mas só iríamos dispor de capacidade de produção em meados de 1980; tínhamos, no entanto, uma linha de aviação comercial na nossa subsidiária Swarangen. Eles não tinham aviação comercial, mas queriam entrar no ramo e então nós trabalhamos até que finalmente conseguimos uma plataforma de termos e condições que refletiam as reais necessidades e objetivos das duas partes. Aí, partiIhávamos a produção mediante uma fórmula de divisão de custos e, ainda, segundo uma outra fórmula, porque, como disse, dispúnhamos de maior capacidade de produção do que de engenharia, tínhamos companhias de mercado separadas, formadas para este empreendimento custado conjuntamente pelas nossas duas empresas e onde nós auferíamos proveitos na companhia de mercado num percentual diferente do das outras áreas. Um acordo muito complicado, no qual uma tremenda dose de energia e despesa ocorreu nos primeiros estágios, antes que finalmente fosse assinado para assim se ter certeza de que correspondia aos objetivos de ambas as partes e era viável. Isso permitiu à SAAB penetrar numa área tecnológica em-que estava por fora - a moderna aviação comercial - e permitiu à Fairchild aumentar mais rapidamente as suas linhas de aviação comercial e ter ainda uma melhor penetração no mercado mundial.

\title{
Desenvolvimento de tecnologia própria. Áreas selecionadas de investimentos
}

Ozílio Carlos da Silva, diretor comercial da Empresa Brasileira de Aeronáutica S/A -

Embraer.

Obviamente, quem produz um produto tecnologicamente avançado, como é o caso da Embraer, que enfrenta pesada competição no mercado internacional, e que age numa área de rápida evolução 
da tecnologia, como aliás o mr. Dealy acabou de mencionar, no caso da empresa que ele dirigiu essas características fazem com que qualquer empresa, para sobreviver neste ambiente, tinha que fazer pesados investimentos no desenvolvimento de tecnologia própria. É praticamente impossível na área aeroespacial, hoje, uma empresa ter porte internacional se não possuir capacidade de desenvolvimento de tecnologia própria. E onde estão esses investimentos em tecnologia? Selecionar-se-ão, a seguir alguns pontos principais onde uma empresa investe pesadamente no desenvolvimento da tecnologia própria. Antes de tudo, e o mais importante, a meu ver, é o treinamento de pessoal, porque a rápida evolução da tecnologia faz com que a obsolência dos equipamentos dos sistemas de testes, dos auxílios para o desenvolvimento, laboratórios, etc., tenham mortalidade muito rápida. A única coisa que não tem uma mortalidade rápida em termos de investimentos é um treinamento eficiente e avançado do pessoal técnico; e esse sempre tem um retorno garantido.

Outro provável investimento é na aquisição de máquinas e equipamentos avançados, para se poder prosseguir acompanhando a velocidade dos concorrentes. Temos um caso recente na Embraer: para entrar num projeto de novo avião de transporte com trinta lugares, no qual só poderia competir com os concorrentes que estão trabalhando no mesmo projeto (aliás:a própria Fairchild é um dos principais concorrentes nesta área) teve que introduzir um projeto de computer aid design, computer aid manufacture, quer dizer, um sistema de projeto de fabricação diretamente comandado por computadores, investimento pesadíssimo em termos financeiros e que dentro de dois ou três anos já estará obsoleto. Portanto, não se pode nem utilizar os métodos tradicionais de amortização desse investimento.

Outra área de pesados investimentos é a construção de laboratórios de ensaio especializado e instalações em geral para construção de protótipos, para a construção de modelos de laboratório, etc. Depois, vem a mão de obra e o material para a construção de protótipos para a preparação dos desenhos, dos projetos e das especificações de fabricação. E, posteriormente, uma fase também cara e longa são os ensaios de desenvolvimento: a colocação do produto em produção seriada e em condições de segurança e de competição no mercado.

Estes são os investimentos que a empresa tem que fazer em tecnologia para que permaneça no seu mercado. Quais são as fontes desses investimentos? E aí é que entra o problema do financiamento a esse desenvolvimento. As fontes tradicionais e aquelas que todos utilizam são:
- o capital próprio, que no caso brasileiro e eu diria em geral - é insuficiente para o volume de investimentos que uma empresa precisa fazer para se manter no mercado;

- os lucros que, ainda mais em época de crise internacional como a que estamos vivendo, são cada vez mais magros e cada vez mais insuficientes para poder sustentar o desenvolvimento de tecnologia no nível requerido.

Então, recorre-se às outras fontes tradicionais: os financiamentos internacionais e mesmo nacionais, que hoje são somente obtidos a taxas altas e mercados raros, com correção cambial, onerando o custo futuro do produto. Para dar apenas um exemplo, a Metal Leve, em 1981, investiu $2 \%$ do seu faturamento em desenvolvimento; a Embraer investiu $12,8 \%$, representando 2,933 bilhões de cruzeiros somente em pesquisa e em desenvolvimento. Certamente $12,8 \%$ do faturamento não foi o lucro da empresa, e ela teve que buscar isso nas fontes tradicionais, ou seja, financiamentos externos, parte de lucro, parte de agências governamentais - tipo Finep, IBEC, BNDES - , as quais proporcionaram $5 \%$ desses recursos, em 1981.

De maneira que isso se torna um limitante muito sério para o desenvolvimento da tecnologia. Eainda mais, que hoje há um outro fenômeno com o qual as empresas que competem no mercado internacional se defrontam, que é o protecionismo cada vez mais virulento, utilizando-se o tipo de financiamento favorecido como argumento de proteção contra a entrada do produto em determinados mercados; caso típico dos americanos, em que não só os incentivos fiscais à exportação utilizados pelo Brasil, como os eventuais incentivos ao desenvolvimento do produto, são computados. Acontece que temos que aprender muito ainda em termos de financiamento e de incentivo à pesquisa e desenvolvimento; aprender no sentido de fazer isso de forma que não fique claramente demonstrado por parte de um governo estrangeiro que queira argüir a existência desse tipo de incentivos, porque no Brasil, quando se toma um financiamento, sem correção monetária, por exemplo, da Finep, isso é publicado em todos os jornais, sai fotografia, etc., qualquer governo que queira demonstrar que aquele produto foi subsidiado, ele tem provas que nós geramos; enquanto que os países avançados utilizam processos discretos de incentivos, muito mais fortes do que os nossos, mas que ninguém consegue provar. Não posso citar o caso da Fairchild porque não a visitei; mas visitei inúmeras empresas americanas, nas quais, desde a guarita do portão de entrada até a mesa do presidente era propriedade do governo americano. Então, tudo isso aqui mencionado: instalações, laboratórios, recursos de projetos, todos esses investimentos tremen- 
dos e que são dificílimos de obter em fontes adequadas, muitas empresas, que trabalham com tecnologia avançada, recebem a título de contratos governamentais, principalmente quando se trata de atividades espaciais e militares, cujas instalações e recursos podem ser usados no desenvolvimento de quaisquer dos produtos da empresa, porque nos contratos isso é permitido, de maneira que são formas mais avançadas de se subsidiar um produto sem que isso apareça claramente publicado no jornal. Eé óbvio que não só na presente situação da economia internacional, mas em qualquer situação, é difícil uma empresa industrial, que precisa manter-se atualizada tecnologicamente, obter recursos para o seu desenvolvimento somente através das fontes clássicas e, principalmente, através do seu capital próprio e de utilização de lucros. Isto está se tornando cada vez mais difícil, senão impossível.

A participação governamental é fundamental e essa participação é justificável porque a criação de tecnologia - houve vários exemplos aqui citados hoje - permite, não só a exportação de produtos tecnologicamente avançados, portanto, ingresso de divisas, criação de emprego, tudo aquilo que estamos cansados de saber e quem vive esse problema sabe perfeitamente das vantagens do sistema.

Complementaria apenas mencionando alguns outros aspectos para os quais talvez, no caso brasileiro, nós precisássemos atentar. Primeiro é que não há possibilidade de uma empresa que trabalha com produto avançado criar toda a tecnologia de que necessita para se manter no mercado. Ela sempre vai ter necessidade, em alguns tópicos da sua atividade, de importar tecnologia e de manter intercâmbio com outras organizações. Então, seria conveniente que os órgãos encarregados do controle dessa importação de tecnologia e de registros de contratos. como por exemplo, o INPI, o Banco Central, etc., criassem alguns mecanismos que facilitassem mais as empresas que comprovadamente investem pesadamente em tecnologia e que desenvolvem tecnologia própria, bem como lhes proporcionassem mais flexibilidade em contratar e fazer acordos de cooperação com outras empresas do exterior, a fim de complementar tópicos necessários para que elas desenvolvam o seu produto de uma forma geral.

Por outro lado, no que diz respeito à exportacão de tecnologia, área em que também a nossa empresa está hoje começando a entrar, nós temos várias competições no mercado internacional, que pre- vêem a fabricação sob licença do nosso produto por outros países. E hoje, além daquelas características, que o dr. Bandeira muito bem ressaltou na sua palestra, cuidados que devem ser tomados nessa exportação, existe um fato novo: é que todo mundo está aprendendo, como o Brasil aprendeu também, a defender a sua tecnologia e a defender a criação de empregos internamente, ou seja, todos os países que querem fabricar o seu produto sob licença estão exigindo liberdade total de comercialização, reexportação, portanto, estão exigindo redução ou praticamente isenção de pagamento de royalties, de licenças, etc. Isso cria para o exportador de tecnologia também um fato novo, a necessidade de aprender a negociar essa exportação, de forma que ele possa competir com os concorrentes que também às vezes prometem muita coisa desse tipo, sem obviamente prejudicar a economia da operação. $\mathrm{O}$ exportador, em suma, vai criar um competidor para o seu produto e depois vai ter que enfrentar esse competidor no mercado internacional. Portanto, a exportação de tecnologia quando se trata de licenças, já não é negociação tão simples como poderia parecer. Além disso, existe uma outra exigência de contrapartida, o equilíbrio de balança e divisas, que torna extremamente complexa a exportação de tecnologia, e também requer, muitas vezes, a formação de verdadeiros pools de negociação, porque, quando há exigência de uma contrapartida ou do equilíbrio de balança e divisas, muitas vezes, tem-se que promover a importação de outros produtos daquela área, para o Brasil, de forma que essa exigência de equilíbrio de divisas possa ser atendida. E muitas vezes isso requer a participação do trading company e de outros tipos de organização que ajudam na montagem do pacote.

O papel que o Itamaraty pode e deve desempenhar nesse tipo de negociação parece relevante, porque se trata de negociação que vai quase sempre envolver governos na sua montagem.

Portanto, resumindo a minha participação, diria que devemos procurar encontrar formas mais inteligentes de financiar o desenvolvimento de tecnologia, para que não só o custo desse desenvolvimento seja possível de ser suportado no preço do produto, como também possa suportar - se não puderem ser cortadas - medidas protecionistas em outros países, principalmente nos países mais desenvolvidos, que constituem, sem dúvida alguma, os mercados mais fortes e mais amplos do mundo e para os quais preferencialmente os produtos de tecnologia avançada são hoje exportados. 